\title{
A APLICABILIDADE DO DIREITO FRATERNO NO ÂMBITO DA MEDIAÇÃO DE CONFLITOS COMO MÉTODO EXTRAJUDICIAL DE TRATAMENTO DE CONFLITO
}

\author{
Luciane Mara Correa Gomes ${ }^{1}$ \\ Tauã Lima Verdan Rangel ${ }^{2}$
}

\begin{abstract}
Resumo
É importante diagnosticar, a humanidade tem estado inclinada a tratar os seus semelhantes de forma distinta da que almeja nas relações sociais, prejudicando a solução de conflitos. Por este prisma, a mediação, com o fim de resolver as celeumas, inspira compreender como o outro absorve as conseqüências deste litígio, quando se põe no lugar do outro. A pesquisa indica as diretrizes que deverão ser adotadas para funcionalidade da mediação; especificamente, ao identificar os conceitos do Direito Fraterno e estabelecer fomento do diálogo neste campo. O aporte teórico é feito em Resta, Pinho, Spengler, adotando metodologia qualitativa por trabalho bibliográfico.
\end{abstract}

Palavras chave: Direito fraterno; mediação de conflitos; cultura do diálogo; relações sociais; métodos adequados de resolução de conflitos.

\section{THE APPLICABILITY OF FRATERNAL LAW IN THE CONTEXT OF CONFLICT MEDIATION AS AN EXTRAJUDICIAL CONFLICT TREATMENT METHOD}

\begin{abstract}
It is important to diagnose, humanity has been inclined to treat its peers in a way different from the one it craves in social relations, hampering the solution of conflicts. From this point of view, mediation, with the purpose of resolving the cries, inspires to understand how the other absorbs the consequences of this litigation, when put in the place of the other. The research indicates the guidelines that should be adopted for mediation functionality; Specifically, by identifying the concepts of Fraternal Law and establishing dialogue in this field. The theoretical contribution is made in Resta, Pinho, Spengler, adopting qualitative methodology by bibliographic work.
\end{abstract}

Keywords: Fraternal law; conflict mediation; culture of dialogue; social relationships; alternative resolution disputes.

\footnotetext{
${ }^{1}$ Mestre em Direito Público e Evolução Social pela Universidade Estácio de Sá. Bacharel em Ciências Jurídicas e Ciências Sociais pela Universidade Federal do Rio de Janeiro. Professora no Centro Universitário Augusto Motta. Membro do Colégio de Professores da Academia Brasileira de Direito Constitucional. E-mail: lucianemara@uol.com.br; link do Lattes: http://lattes.cnpq.br/7142619530244859

2 Bolsista CAPES. Doutorando vinculado ao Programa de Pós-Graduação em Sociologia e Direito da Universidade Federal Fluminense. Mestre em Ciências Jurídicas e Sociais pelo Programa de Pós-Graduação em Sociologia e Direito da Universidade Federal Fluminense. Especialista em Práticas Processuais Processo Civil, Processo Penal e Processo do Trabalho pelo Centro Universitário São Camilo. Professor na Faculdade Metropolitana São Carlos - Bom Jesus do Itabapoana e na Multivix - Unidade Cachoeiro de Itapemirim-ES. E-mail: taua_verdan2@hotmail.com; link do Lattes: http://lattes.cnpq.br/8802878793841195
} 


\section{A APLICABILIDADE DO DIREITO FRATERNO NO ÂMBITO DA MEDIAÇÃO DE CONFLITOS COMO MÉTODO EXTRAJUDICIAL DE TRATAMENTO DE CONFLITO}

\section{INTRODUÇÃO}

Críticas incisivas são proferidas no que se refere ao estado em que se encontra o campo judiciário, com incalculáveis demandas propostas, muitas sob a pecha de "cultura de massa", outras, pela denotável postura estatal em não fiscalizar os serviços públicos delegados, todo este arcabouço, aditivado por legislações arcaicas e não compatíveis com os novos meios de produção, cercados ainda de incompatível quadro de recursos humanos, culminam numa crise do poder judiciário, cuja repercussão é a descrença na virtude da Justiça.

Se o Estado não está capacitado para desempenhar o papel de garantidor da ordem social justa, a sua legitimidade está sendo posta em cheque, pelo singular fator de não executar a prestação de serviço judiciário a contento, prejudicando assim o interesse do cidadão mediano. Posição já salientada por doutrinadores de escol, a aparente solução estaria não em determinar o resultado prático pretendido das demandas judiciais a partir de meios onde as partes envolvidas assim pudessem chegar ao consenso, desbaratando os nós do conflito instalado e que o Poder Judiciário pudesse consolidar, para que houvesse o caráter coercitivo e imperativo do avençado, apaziguar os ânimos conturbados pela dualidade de opiniões e que os envolvidos voltassem a se relacionar de forma digna, onde o papel social do Poder Judiciário seja admoestar as partes envolvidas.

Não obstante o que se apresenta, é necessário para os agentes sociais, não é um caderno de como se realiza uma mediação de conflitos, pois, para grande parte da sociedade, trata-se apenas de mais uma etapa na solução do problema, não há para a visão desta camada da sociedade, em especial para aquelas que não possuem a cultura de buscar o Poder Judiciário para pacificar suas crises de natureza jurídica no convívio social, não se verbaliza apenas a mediação como entender as razões e motivos da conduta ou postura do outro. Pensar isto é ser prematuro em assumir a posição de que a mediação é a tábua de salvação da crise institucional do Poder Judiciário, a inocência não é uma virtude que não nos é mais permitida. Isto porque a mediação está regulamentada, sob forma de lei, a cerca de dois anos e pouco se caminhou até o presente momento e ainda não somos capazes de ouvir o outro, sentir o que o outro sente. Não são meras nuances de condão psicológico, são diretrizes principiológicas que estão nas matrizes filosóficas e se 
sedimentam no Direito, a partir de uma visão cosmopolita do outro ser igual a mim, gozar das mesmas liberdades e juntos desenvolvermos laços fraternais, eis que são referendados pelas Revoluções Americana e Francesa, como meios de união entre e dentre os povos.

Sendo assim, a busca do princípio da fraternidade deve estar limitada aquela gama de direitos que diz respeito à coletividade, posição esta que num primeiro momento pode invadir o pensamento do leitor, o que não deixa de ser uma das suas etapas.Desta forma, é necessário estabelecer o caminho a ser perquirido por este trabalho, cujo objetivo é entender a aplicação do Direito fraterno na solução dos conflitos, para que os litígios tenham efetiva participação dos envolvidos, já que a legislação processual transmite aos interessados os deveres de colaboração e de condução das demandas em usufruto do princípio da autonomia de vontade das partes.

Como todo resultado de um processo interessa a toda sociedade, é oportuno refletir até que ponto é oportuna a aplicação do Direito Fraterno, como se identifica e a sua aplicação, pois integra os objetivos específicos deste trabalho, ficando a cargo do entender a cultura do dialogo no âmbito da mediação um dos muitos métodos de efetivar a participação democrática dos interessados na solução do litígio e por derradeiro, avaliar se esta prática capacita o envolvido na construção da decisão desta celeuma. Amparado por pesquisa bibliográfica, o artigo traz o posicionamento de Elígio Resta, Humberto Dalla Bernardino de Pinho, Fabiana Marion Spengler para delinear os aspectos do Direito Fraterno numa abordagem qualitativa.

\section{O DIREITO FRATERNO COMO ALICERCE TEÓRICO DOS MÉTODOS EXTRAJUDICIAIS DE TRATAMENTO DE CONFLITOS}

Diante das ponderações apresentadas até o momento, cuida estabelecer uma crítica a oferta monopolista de justiça que foi incorporada no interior do sistema de jurisdição, delegado a receber e a regular uma escalada de conflitualidade. Entretanto, o que culminou a altos índices de ineficiência do sistema de jurisdição está arrimado no crescimento vertiginoso das expectativas e das perguntas a isso referidas. "Em sentido técnico, chama-se explosão da litigiosidade, possuindo muitas causas, nunca analisadas com profundidade. O fato é que a atenção sempre esteve mais voltada para os 'remédios' (no sentido de constantes reformas nas normas)" (SPENGLER, 2006, p. 51), em detrimento da abordagem das causas da litigiosidade crescente, que, tradicionalmente, 


\section{A APLICABILIDADE DO DIREITO FRATERNO NO ÂMBITO DA MEDIAÇÃO DE CONFLITOS COMO MÉTODO EXTRAJUDICIAL DE TRATAMENTO DE CONFLITO}

encontra tradução na linguagem jurídica e que se dirige à jurisdição sob a forma irrefreável de procedimentos judiciários.

Ao lado disso, é cristalino que a regulação dos conflitos, dentro de uma sociedade, se transforma no tempo e no espaço, estabelecendo os remédios a serem aplicados, sendo que a ineficácia em sua aplicação desencadeia a novação equivocada de que a causa é a falta de recursos estruturais, materiais e pessoais, além de outros. Ora, o remédio age apenas sobre a ferida existente, não atacando a causa desencadeadora. É justamente, nesse cenário, impulsionado pela cultura adversarial abordada anteriormente, que o problema tende a ser agravado, porquanto reafirma uma cultura adversarial, pautada na ideologia do ganhador-perdedor e alimentada pela rivalidade geradora do conflito. Assim, em busca do estabelecimento de uma resposta, na grande maioria dos conflitos, ocorre a demanda processual, em que, como dito algures, a arena da litigiosidade ganha contornos mais robustos e as partes processuais passam a se encarar como rivais.

Resolver o conflito judicialmente, porém, significa recorrer ao magistrado e atribuir a ele o poder de dizer quem ganha e quem perde a demanda. É oportuno consignar, em tal cenário, o fortalecimento da estadania e o enfraquecimento da cidadania ativa, na qual os envolvidos no conflito possuem um comportamento amadurecido apto a conduzir a administração do litígio e, em conjunto, apresentar soluções. "Vai nesse sentido a afirmativa de que quando se vai ao juiz se perde a face, uma vez que, imbuído do poder contratual que todos os cidadãos atribuem ao Estado, sendo por ele empossado, o magistrado regula os conflitos graças à monopolização legítima da força" (SPENGLER, 2006, p. 52).

Em alinho com as ponderações apresentadas até o momento, cuida assinalar que a proposta fraterna substancializa, segundo as ponderações apresentadas por Ghisleni e Spengler (2011), o embasamento teórico da mediação e dos demais métodos extrajudiciais de tratamento de conflitos sociais, porquanto insere uma parcela de complexidade no primado do justo sobre o bom, buscando estabelecer contornos dessemelhantes daqueles que tender a emoldurar as relações. Sem embargo, há que sustentar, também, que ao postulado da fraternidade está atrelado, imperiosamente, o ideário de amizade, "na medida em que prevê a "comunhão de destinos derivada do nascimento e independente das diferenças"” (GHISLENI; SPENGLER, 2011, p. 24). Para 
Eligio Resta (2004), o Direito Fraterno compreende um modelo de direito que abandona a tradicional visão fechada da cidadania e passa a olhar em direção à nova forma de cosmopolitismo que não é representada pelo mercado, mas pela necessidade universalista de respeito aos direitos humanos que vai se impondo ao egoísmo ou pelos poderes informais que à sua sombra governam e decidem.

Entretanto, é imprescindível destacar que o vocábulo fraternidade, em tal contexto, possui um sentido vagamente anacrônico, porquanto, quando comparada a outros ideais presentes no cenário da revolução iluminista, pode ser considerado dotado de menor proeminência, eis permaneceu inédita e não resolvida em relação aos demais temas da liberdade e da igualdade. Mais que isso, a fraternidade indicava apenas um dispositivo de etérea solidariedade entre as nações; guardando maior vinculação com os princípios de um direito internacional nascente, que deixava intacta, tal como pressupunha uma comunidade política assentada nos corolários dos Estados nacionais, porém sua solidificação é capaz de inaugurar uma nova oportunidade no tratamento de conflitos (RESTA, 2004, p. 09-12).

Dessa forma, a vinculação entre direito e fraternidade, além de ser uma tentativa de valorizar uma possibilidade diferente, recoloca em destaque um modelo de regra da comunidade política: modelo não vencedor, mas possível. Destarte, é um trecho do direito vivo que não deve ser analisado sempre como o direito vencedor. Ora, por meio do binômio em comento retorna um modelo convencional de direito, “jurado conjuntamente' entre irmãos e não imposto, como se diz, pelo 'pai senhor da guerra'. Jurado conjuntamente, mas não produzido por um 'conluio"” (GHISLENI; SPENGLER, 2011, p. 25). Em decorrência disso, é decisivamente não violento, ou seja, capaz de não se apropriar da caracterizadora violência pertencente ao querer combater. Em arremate, Humberto Dalla Bernardina de Pinho e Michele Paumgartten (s.d.) evidenciam que um dos pilares mais relevantes do Direito Fraterno encontra consolidação sob o alicerce de uma sociedade humana, retratando um Direito não violento, despido da beligerância e dos enfrentamentos desnecessários, buscando, doutro viés, a inclusão e a ruptura do binômio ganhador-perdedor/amigo-inimigo, convenção arraigada do processo judicial tradicional.

É oportuno, ainda, apontar que o Direito Fraterno encontra sustentação por meio dos direitos humanos, que se estabeleceram com o decurso da história da humanidade e que possuem aspecto de universalidade, eis que são aplicados a todos os cidadãos. Ao 


\section{A APLICABILIDADE DO DIREITO FRATERNO NO ÂMBITO DA MEDIAÇÃO DE CONFLITOS COMO MÉTODO EXTRAJUDICIAL DE TRATAMENTO DE CONFLITO}

lado disso, os direitos humanos resultaram, por consequência, de múltiplos processos históricos e que ainda hoje sofrem alterações em decorrência da globalização mundial. Em complementação, Resta (2004) sublinha que o Direito Fraterno coincide com o locusde reflexão associados ao tema dos Direitos Humanos, conferindo uma consciência a mais, a saber: a de que a humanidade é apenas um lugar comum, somente em cujo interior é possível pensar no reconhecimento e na tutela. É necessário, também, estabelecer a diferença existente entre ser homem e ter humanidade. Há que se destacar, nesta linha de exposição, que o fato de ser homem não assegura que haja o sentimento singular de humanidade; a linguagem, com a variabilidade de sentido que encerra, substancializa um infinito observatório dos paradoxos com os quais o ser humano convive.

Ainda no que pertine aos direitos humanos, cuida destacar que, ao mesmo tempo, em que eles somente podem ser ameaçados pela própria humanidade, é em decorrência desta que entra em vigor. Logo, o Direito Fraterno se apresenta como um instrumento por meio do qual é possível crescer um processo de autorresponsabilização, desde que o reconhecimento do compartilhamento se libere da rivalidade destrutiva típica do modelo adversarial do sistema processual brasileiro. "Podem ser definidos como o direito inerente a toda e qualquer pessoa, visando à proteção e resguardo da integridade dos cidadãos. $\mathrm{O}$ interessante é que os direitos humanos vêm adquirindo cada vez mais solidez com o evoluir da humanidade" (GHISLENI; SPENGLER, 2011, p. 25), possuindo contornos claramente internacionais em face da criação de normas de proteção internacional da pessoa humana. Ademais, encontram claro liame com a ideia de cidadania, como bem explicita Eligio Resta:

[...] o seu olhar voltado para além do confim, para proximidades distantes, requer revogações decisivas daquele "direito de cidadania", que é, desde sempre, lugar de exclusão através de um ethnos. Por isso, a sua forma é aquela dos direitos humanos, contanto que eles sejam esvaziados da metafísica. O olhar vai para a humanidade como um "lugar comum", e não como a abstração que confunde tudo e mascara as diferenças. Os direitos humanos têm uma dimensão "ecológica", são espaço no qual as duplas opositivas são novamente compreendidas: isto nos leva à conscientização de que os direitos humanos podem ser ameaçados sempre e somente pela própria humanidade; mas podem ser tutelados sempre e somente pela própria humanidade; não por uma natureza, um Deus, um Terceiro, qualquer outra abstração metafísica, mas pelos homens de carne e osso, por nós, na vida quotidiana (RESTA, 2011, p. 134). 
O novo modelo de composição dos conflitos que floresce no Direito Fraterno está centrado na criação de regras de compartilhamentos e de convivência mútua que desbordam dos tradicionais litígios judiciais, arvorando formas de inclusão de proteção dos direitos fundamentais. Em uma seara essencialmente judicial, existem mecanismos extrajudiciais $^{3}$ de tratamento das demandas, sendo possível citar a conciliação, a arbitragem e a mediação. Cuida-se, portanto, de elementos que possuem como ponto comum serem extrajudiciais, porém não estranhos ao Poder Judiciário, operando na busca da faceperdida das partes processuais numa relação de cooperação pactuada e convencionada, estabelecendo uma justiça de proximidade e, sobremaneira, uma filosofia de justiça calcada no modelo restaurativo que compreende estruturas de composição e gestão do conflito menos autoritariamente decisivo, como observa Resta (2004).

Mais que isso, há que reconhecer que o conflito também se tornará essencialmente prejudicial quando os mecanismos para tratamento são considerados inadequados, por retirar do conflito o que ele tem de melhor, a saber: sua capacidade de gerar a satisfação de interesses e resoluções construtivas. "Quando esses mecanismos são descartados, a função do conflito é a produção de violência ou outros conflitos. A decisão judicial pode interromper ou acelerar o processo de causa e efeito, mas não propicia a mudança necessária para a evolução que o conflito pode provocar" (PINHO; PAUMGARTTEN, s.d., p. 08). Mais que isso, a questão determinante encerrada na função do conflito será a escolha do processo de tratamento para alcançar os resultados buscados. Ora, o processo competitivo adversarial estabelece ganhadores e perdedores, ao passo que o processo cooperativo, assentado na doutrina do Direito Fraterno, determina apenas ganhadores. "Entende-se até de um modo amplo, que mesmo a parte vença uma disputa, não logra um conflito construtivo, pois a satisfação de objetivos unilaterais, unicamente individuais, cristaliza o egocentrismo, auxiliam o totalitarismo e provocam com o tempo, consequências sempre destrutivas" (PINHO; PAUMGARTTEN, s.d., p. 08).

\footnotetext{
${ }^{3}$ Em que pesem os debates existentes sobre a nomenclatura, havendo a denominação métodos alternativos de tratamento de conflitos e métodos extrajudiciais de tratamento de conflitos, no presente a segunda será a empregada, porquanto, para o objeto eleito, confere protagonismo aos envolvidos no conflito, reafirmando as bases de cidadania ativa, autorresponsabilização e autonomia na condução da administração do conflito e na construção de uma resposta que decorra dos anseios de ambos e não calcado na imposição do Estadojuiz fortalecido.
} 


\section{A APLICABILIDADE DO DIREITO FRATERNO NO ÂMBITO DA MEDIAÇÃO DE CONFLITOS COMO MÉTODO EXTRAJUDICIAL DE TRATAMENTO DE CONFLITO}

Em tal trilha de insatisfação, cujo nascedouro está ancorado na insuficiência estatal para atender as demandas sociais e os conflitos de interesse, de maneira geral, estão delineados, com entusiasmo, o sistema de métodos alternativos à jurisdição ou alternative dispute resolution(ADR) para o tratamento dos conflitos, assentado numa prática discursiva, criando através do diálogo e não da força coercitiva, um tratamento para o conflito, cuja legitimidade deste resultado encontra suas bases no próprio processo comunicativo que lhe originou. Assim, com o escopo de avançar no exame da temática, faz-se imprescindível analisar, pormenorizadamente, a mediação como método extrajudicial de tratamento de conflito e a valorização do diálogo para administrar o conflito e na promoção da cidadania ativa, o que será feito na seção subsequente.

\section{MEDIAÇÃO COMUNITÁRIA COMO AXIOMA DE EFETIVAÇÃO DA DEMOCRACIA PARTICIPATIVA: O FOMENTO DO DIÁlOGO NA COMUNIDADE PARA A CONSTRUÇÃO DE DECISÕES COLETIVAS}

À sombra do pontuado até o momento, cuida anotar que, em sede de mediação, subsiste um cuidado, por parte do mediador, de promover a facilitação do diálogo entre as partes, de modo a viabilizar a comunicação pacífica e a discussão efetiva dos conflitos. "O ato de conversar (ou seja, não somente falar, mas também ouvir) e de poder olhar o problema de novas maneiras ajuda as pessoas a encontrarem, juntas, os melhores caminhos para a solução de seus conflitos" (BRASIL, 2008, p. 16). Nesta linha, conforme Carvalho (s.d., p. 04) destacou, diálogo não tem seu sentido associado apenas a manutenção de uma conversa, mas sim na possibilidade de se colocar no lugar do outro, a fim de compreender seu ponto de vista, respeitar a opinião alheia, compartilhar as experiências vividas, partilhar a informação disponível e tolerar longas discussões para se alcançar um consenso que satisfaça tanto os envolvidos quanto à comunidade direta $\mathrm{e}$ indiretamente afetada. Dentre os principais objetivos adotados por este procedimento, é possível mencionar a solução extrajudicial dos conflitos. Entrementes, em que pese sua importância, cuida destacar que essa não dever ser o único fito a ser ambicionado na mediação de conflitos; ao reverso, outros objetivos da mediação devem ser enfocados, como, por exemplo, a má administração dos conflitos, o que permite o tratamento 
adequado do problema e a manutenção dos vínculos afetivos existente entres as partes, tal como a busca pela inclusão social e da pacificação social.

Neste aspecto, verifica-se, por mais uma vez, que a mediação é instrumento apto ao desenvolvimento do diálogo entre os envolvidos, com o auxílio e participação da comunidade, de modo geral, para que seja possível a superação do litígio, bem como a afirmação dos valores estruturantes da própria democracia participativa, despertando no cidadão a necessidade de um papel ativo. "Busca-se trabalhar a mediação como instrumento de promoção da paz social e de diminuição da violência. Assim, a paz social é entendida como algo que vai além da inexistência de violência física e moral, passando pela necessidade de efetivação dos direitos fundamentais" (SALES; ALENCAR; FEITOSA, 2009, p. 291).Com efeito, a estruturação de um diálogo entre os envolvidos e a pacificação social não são alcançadas em comunidades em que há fome, elevados índices de desemprego, indivíduos realizando trabalhos forçados ou mesmo em condição análoga à de escravidão, maciça exploração sexual infantil, carência de moradias dignas, baixos níveis de educação e saúde, além de outras mazelas sociais que interferem, de maneira direta, no desenvolvimento harmônico e sustentável da sociedade, afetando, inclusive, na paz social.

Fomenta-se a paz quando se resolve e previne a administração inoperante dos conflitos; quando se busca promover o diálogo; quando se possibilita a discussão sobre direitos e deveres, bem como responsabilidade social; quando se viabiliza a substituição o sentimento de competição, inerente ao sistema adversarial estruturado no Brasil, pelo ideário de cooperação. "É nos espaços de participação construídos através de uma mediação democrática que os envolvidos aprendem e vivenciam a cidadania. Rompendo o silêncio, abre-se à participação para além dos espaços privados da comunidade" (NASCIMENTO, 2010), contribuindo, assim, para o fortalecimento deste ambiente social e, secundariamente, na construção de um Estado que propicie a democracia participativa em seus plurais desdobramentos. Ora, a mediação, na condição instrumento pacífico e participativo de resolução de conflitos, vindica das partes envolvidas o diálogo acerca dos problemas, dos comportamentos, dos direitos e deveres de cada um, sendo que toda essa discussão se assenta na forma cooperativa, fortalecendo o compromisso ético com o diálogo honesto. 


\title{
A APLICABILIDADE DO DIREITO FRATERNO NO ÂMBITO DA MEDIAÇÃO DE CONFLITOS COMO MÉTODO EXTRAJUDICIAL DE TRATAMENTO DE CONFLITO
}

\begin{abstract}
Nesse contexto, no âmbito comunitário, em especial, o procedimento de mediação de conflitos promove uma maior responsabilidade e participação da comunidade na solução dos seus conflitos, o que contribui favoravelmente para a preservação das relações, a satisfação dos interesses de todas as partes e a economia de custos de tempo e dinheiro na solução do conflito. É dada maior relevância à necessidade de tornar os cidadãos conscientes do seu poder para resolverem os seus conflitos através do diálogo produtivo, construindo pontes que edificam relações cooperativas entre os membros da comunidade, abrindo novos caminhos para uma positiva transformação sociocultural. A mediação comunitária realiza-se nos bairros de periferia, com o intuito de propiciar à comunidade a conscientização de seus direitos e deveres, além da resolução e prevenção de conflitos em busca da paz social. Essa mediação permite a criação de maiores laços entre os envolvidos, incentivando a participação ativa dos membros daquela comunidade na vida social, ensinando-os a pensarem coletivamente e não mais individualmente. (CARVALHO, s.d., p. 04).
\end{abstract}

Há que se reconhecer, neste cenário, que o fomento ao empoderamento dos indivíduos propicia um processo transformativo aberto e externado pela participação cidadã, culminando na autonomia de tratamento de conflitos, ao tempo em que fortalece o desenvolvimento comunitário. Ao lado disso, os objetivos ambicionados pela mediação em comento consistem no desenvolvimento entre a população de valores, conhecimentos e comportamentos que conduzam ao fortalecimento de uma cultura de paz. De igual modo, em substituição a tradição visão adversarial ganhador-perdedor, enfatiza-se a relação entre os valores e práticas voltados à realização da democracia e da convivência pacífica, contribuindo para a construção de um consenso entre os indivíduos, no qual o respeito e a tolerância são os aspectos característicos mais proeminentes. Há um caminho para o exercício da cidadania participativa, consistente na possibilidade da busca conjunta, consciente e amadurecida das partes envolvidas em prol do tratamento do conflito existente. Vezzula (2010, p. 56) salienta que "a mediação, recuperando os conceitos de participação responsável da comunidade na abordagem e na resolução dos conflitos entre seus integrantes, foi fortalecendo a sua identidade e, com isso, consolidou a capacidade de protagonismo dos moradores".

“A mediação nas comunidades traduz o exercício de cidadania e de democracia, pois permite que os cidadãos, até então socialmente excluídos, resolvam por si mesmos seus conflitos com o auxílio de um mediador” (CARVALHO, s.d., p. 05). Com efeito, por estar calcada em uma mudança de cultura, a mediação possibilita aos indivíduos, até então, marginalizados a possibilidade de terem responsabilidade sobre suas vidas e serem incluídos socialmente, reafirmando o preceito basilar de empoderamento dos envolvidos. 
Mais que simplesmente dialogar (conversar), a abordagem do conflito, a partir de uma perspectiva pautada na responsabilidade solidária e compartilhada, assegura aos mediandos a construção de um consenso decorrente da confluência de vontades, no qual se deteriora a ideologia de ganhador-perdedor, edificando, em seu lugar, uma doutrina em que ambas as partes são exitosas ao final. Há uma participação direta dos envolvidos na tomada de decisão, de maneira que o consenso atingido reflete a vontade livre, consciente e amadurecida dos envolvidos, exercendo uma democracia participativa plena, sem mitigações ou obstáculos, o que repercutirá diretamente na qualidade de vida.

Convém destacar que "a mediação desenvolvida em bairros das cidades (mediação comunitária) propicia o diálogo entre as pessoas que convivem diariamente, auxiliando na solução dos seus conflitos e contribuindo para a construção da paz social" (SALES; ALENCAR; FEITOSA, 2009, p. 292). Ora, como a prática da mediação estabelece a reclamação ativa dos envolvidos no tratamento de conflitos, passa-se a não apenas a debater sobre questões de feição individual, mas também questões de aspecto coletivo. As experiências brasileiras em mediação ${ }^{4-5}$, especialmente aquelas realizadas nas periferias dos municípios, têm revelado mudanças de comportamento das pessoas: tornaram-se mais participativas nas decisões individuais e coletivas, refletindo a conjunção de esforços entre os envolvidos, compartilhando a responsabilidade em relação ao tratamento do conflito. É possível, assim, observar que a mediação, ao fomentar o empoderamento dos indivíduos, na construção dos consensos e responsabilidade compartilhada, também alimenta a participação do cidadão na tomada de decisões, conscientizando-o não apenas acerca das questões individuais, mas também sobre as questões coletivas e seus desdobramentos.

\footnotetext{
${ }^{4}$ Neste sentido, é possível citar, como exemplo paradigmático de projeto bem sucedido de mediação comunitária, o Projeto "Balcão de Direitos", desenvolvido pela ONG Viva Rio. Falcão (s.d., p. 02), ao discorrer acerca do programa, descreve que: "O Programa Balcão de Direitos do Viva Rioexiste há oito anos nas favelas do Rio deJaneiro. São ao todo cinco balcões, instalados em prédios comunitários, onde estudantese outros voluntários atendem à comunidade. Mais de 70 mil atendimentos já foramfeitos, de cálculos trabalhistas a mediação e conciliação, passando por orientaçãojurídica em processos judiciais. Nos primeiros anos, cerca de $25 \%$ dos serviçosdemandados se relacionavam com ações judiciais. Hoje, esse número caiu para cerca de $15 \%$. O que demonstra que, na medida em que a comunidade cria seus própriosmecanismos de resolução de conflitos, a procura pelo Judiciário tende a ser menor".

${ }^{5}$ É possível, também, citar o Programa de Núcleos de Mediação Comunitária, fomentado pelo Ministério Público do Estado do Ceará, e o Programa de Justiça Comunitária, desenvolvido pelo Tribunal de Justiça do Distrito Federal e Territórios, que, dentre as ferramentas desenvolvidas, utiliza a mediação comunitária e, em termos estatísticos, atendendo 774 (setecentas e setenta e quatro) pessoas (BRASIL, 2008, p.80).
} 


\section{AAPLICABILIDADE DO DIREITO FRATERNO NO ÂMBITO DA MEDIAÇÃO DE CONFLITOS COMO MÉTODO EXTRAJUDICIAL DE TRATAMENTO DE CONFLITO}

4 CONSIDERAÇÕES FINAIS

A problemática que cerca a aplicação do Direito esteve no entorno de dizer quem tem a propriedade sobre um bem, sobre um determinado fato ou ainda sobre como imputar a norma, numa fase da comunidade global entre ser de esquerda ou ser de direita, se assim fossemos delinear a posição do Direito Fraterno ele estaria acima, já que não está vinculado ao dogmatismo, está próximo da compreensão e do diálogo para rever conceitos e, principalmente, os preconceitos, já que trata de visão cosmopolita. Não pertence a nenhuma tribo ou a nenhum lugar comum, não tem dono, pois está pari passu com a Justiça. O Direito Fraterno tende a libertar de paradigmas arcaicos quando se presta a construir alicerces para a efetivação dos direitos fundamentais.

Sua posição no campo da mediação de conflitos não está destinada a atender políticas públicas “de faz-de-conta que há inclusão social”, uma vez que deve estar destinada a construir nos envolvidos praticas de dialogo para obtenção dos resultados que melhor interessam as partes litigantes. Mediação tem por fim recompor a trama na teia social rompida por algum fator e que o acesso a tais técnicas não devem estar comprometidas em repousar sob as mãos dos agentes inseridos no campo judiciário, pelo contrário, os indivíduos devem, para efetivar a diretriz processual de colaboração, saber falar a respeito daquilo que atravessa o curso da normalidade das relações sociais, sem ousar a definir o que é normal.

Como exigir a participação democrática se não há construção de indivíduos atuantes, sendo aqui muito bem aplicável o nível de transgressão a que o Direito Fraterno se propõe, as diferenças são existentes e pertinentes aos grupos sociais, mas aharmonização que seria o ponto nodal do viver em comunidade, é que deve ser posta em evidência. Somente pela construção, em especial nas periferias dos municípios, é que os indivíduos podem se sentir atuantes, já que o conhecer a condição é que torna a possibilidade da mediação uma responsabilidade individual e plúrima.

\section{REFERÊNCIAS}

ANDRADE, Daniela Meirelles; CASTRO, Carolina Lescura de Carvalho; PEREIRA, José Roberto. Cidadania ou "estadania" na gestão pública brasileira. Revista de 
Administração Pública, Rio de Janeiro, n. 46, v. 01, jan.-fev. 2012, p. 177-190.

Disponível em: <http://www.scielo.br/pdf/rap/v46n1/v46n1a09.pdf $>$. Acesso em 20 ago. 2017.

BACELLAR, Roberto Portugal. Juizados Especiais: A Nova Mediação

Paraprocessual.São Paulo: Editora Revista dos Tribunais, 2003.

BENEVIDES, Maria Victoria de Mesquita. Cidadania e Democracia. Revista Lua Nova, n. 33, 1994, p. 05-16. Disponível em: <http://www.scielo.br/pdf/ln/n33/a02n33.pdf>.

Acesso em 20 ago. 2017.

BEZERRA, Tício. A Mediação enquanto instrumento de Emancipação da Cidadania e de Democratização da Justiça e do Direito.Revista Direito \& Sensibilidade, 2011, p. 211-226. Disponível em: < http://seer.bce.unb.br/index.php/enedex/issue/current>. Acesso em 20 ago. 2017.

BONAVIDES, Paulo. Curso de Direito Constitucional. 21 ed. atual. São Paulo: Editora Malheiros Ltda., 2007.

BRASIL. Ministério da Justiça. O que é Justiça Comunitária?Disponível em: $<$ http://www.tjdft.jus.br>. Brasília, 2008, 123p. Acesso 20 ago. 2017.

CARVAlHO, Ana Karine Pessoa Cavalcante Miranda Paes de. Mediação Comunitária: Um Caminho para a práxis cidadã e democrática? Disponível em:

$<$ http://www.mpce.mp.br/nespeciais/nucleomed/publicacoes/artigos/mediacao.comunita ria.caminho.para.a.praxis.cidada.pdf $>$. Acesso em 20 ago. 2017.

CARVALHO, José Murilo.Cidadania no Brasil: o longo caminho. 9. ed. Rio de Janeiro: Civilização Brasileira, 2007.

Cidadania, estadania, apatia. Jornal do Brasil, Rio de Janeiro, p. 8, 24

jun. 2001.

CEARÁ (ESTADO). Ministério Público do Estado do Ceará. Disponível em: <www.mpce.mp.br>. Acesso em 20 ago. 2017.

FALCÃO, Joaquim. Balcão de Direitos. Disponível em:

$<$ http://gajop.org.br/justicacidada/wp-content/uploads/Balcao-de-direitos.pdf $>$. Acesso em 20 ago. 2017.

FERREIRA FILHO, Manoel Gonçalves. Direitos Humanos Fundamentais. 6 ed. São Paulo: Editora Saraiva, 2004.

FOLEY, Gláucia Falsarella. A Justiça Comunitária para Emancipação. In: SPENGLER, Fabiana Marion; LUCAS, Doglas César (org.). Justiça Restaurativa e Mediação:

Politicas Públicas no Tratamento dos Conflitos Sociais. Ijuí: Ed. Unijuí, 2011.

FRONZAGLIA, Paulo M.L. Estado, cidadania e políticas de bem-estar no Brasil: uma abordagem histórica. Revista Mackenzie, São Paulo, n. 3, B07, 2007. 


\section{AAPLICABILIDADE DO DIREITO FRATERNO NO ÂMBITO DA MEDIAÇÃO DE CONFLITOS COMO MÉTODO EXTRAJUDICIAL DE TRATAMENTO DE CONFLITO}

GARCIA, Cláudia Moreira Hehr; VERDAN, Tauã Lima. A Mediação no Novo Código de Processo Civil Brasileiro: Críticas à Efetivação do Instituto de Composição de Litígios, a partir de uma análise construtiva das tradições Civil Law e Common Law. In: PINHO, Humberto Dalla Bernardinade; et all. (org.). Mediação Judicial e Garantias Constitucionais.Niterói: Editora do PPGSD, 2013.

GARCIA, Gustavo S. Prado. Estadania x cidadania. Disponível em:

$<\mathrm{http}$ ://www.pradogarcia.com.br/index.php?option=com_content\&task=view\&id=60\&I temid $=7>$. Acesso em 20 ago. 2017.

GHISLENI, Ana Carolina; SPENGLER, Fabiana Marion. Mediação de conflitos a partir do Direito Fraterno. Santa Cruz doSul: EDUNISC, 2011.

GUARESCHI, P. A. Pressupostos epistemológicos implícitos no conceito de Liberação. In: GUZZO, R.S.L.; LACERDA JUNIOR, F. (Org.). Psicologia Social para a América Latina: o resgate da Psicologia da Libertação. Campinas: Editora Alínea, 2009.

LOPES, Carla Patrícia Frade Nogueira. Mediação Comunitária. In: Seminário de Mediação e Conciliação do TJDFT: Reflexões e Desafios, 2012, Brasília-DF. Disponível em: $<$ http://www.tjdft.jus.br/institucional/escola-de-administracaojudiciaria/revista-mediacao-conciliacao-2012>. Acesso em 20 ago. 2017.

MELLUCCI, A. Social Movements and the Democratization of Everyday Life.Civil Society and the State.Londres: Verso, 1988.

MENDONÇA, AngelaHaraBuonomo. Mediação Comunitária. Uma Ferramenta de Acesso à Justiça? Mestrado (Dissertação). Fundação Getúlio Vargas: Rio de Janeiro, 2006. Disponível em: <http://bibliotecadigital.fgv.br>. Acesso em 20 ago. 2017.

MONTORO, André Franco. Federalismo e o fortalecimento do poder local no Brasil e na Alemanha. Rio de Janeiro: Fundação Konrad Adenauer, 2002.

MORAIS, José Luis Bolzan de; SPENGLER, Fabiana Marion. Mediação e Arbitragem: Alternativas à jurisdição. 2. ed. rev. e ampl. Porto Alegre: Livraria do Advogado, 2008.

MOREIRA, Sandra Mara Vale. Mediação e Democracia: uma abordagem contemporânea da resolução de conflito. Mestrado (Dissertação). Universidade de Fortaleza. Fundação Edson Queiroz: Fortaleza, 2007.

MOURA, Joana Tereza Vaz; SILVA, Marcelo Kunrath. Atores sociais em espaços de ampliação da democracia: as redes sociais em perspectiva. Revista Sociologia Política, Curitiba, v. 16, n. suplementar, ago. 2008, p. 43-54.

NASCIMENTO, Vanessa do Carmo. Mediação comunitária como meio de efetivação da democracia participativa. Ambito Jurídico, Rio Grande, a. 13, n. 83, dez. 2010.

Disponível em: <http://www.ambito-juridico.com.br>. Acesso em 20 ago. 2017. 
NUNES, Dierle José Coelho Nunes. Processo jurisdicional democrático. Uma análise crítica das reformas processuais. Curitiba: Juruá, 2011.

PINHO, Humberto Dalla Bernardina de; PAUMGARTTEN, Michele. $O$ acesso à justiça e o uso da mediação na resolução dos conflitos submetidos ao Poder Judiciário. Disponível em: $<$ http://www.reajdd.com.br/html/humberto.pdf $>$. Acesso em 20 ago. 2017.

RESTA, Elígio. O Direito Fraterno.VIAL, Sandra Regina Martini (trad.). Santa Cruz do Sul: EDUNISC, 2004.

RIBEIRO, Luiz Cesar Queiróz. Desafios da construção da cidadania na metrópole brasileira. Sociedade e Estado, Brasília, v. 22, n. 3, set. dez. 2007, p. 525-544.

Disponível em: <http://www.scielo.br/pdf/se/v22n3/03.pdf>. Acesso em 20 ago. 2017.

RIOS, Paula Lucas. Mediação Familiar: Estudo Preliminar para uma Regulamentação Legal da Mediação Familiar em Portugal. Verbo Jurídico, v. 2, 2005. Disponível em: $<$ http://www.verbojuridico.com>. Acesso em 20 ago. 2017.

SALES, Lília Maia de Moraes; ALENCAR, Emanuela Cardoso O. de; FEITOSA, Gustavo Raposo. Mediação de Conflitos Sociais, Polícia Comunitária e Segurança Pública. Revista Sequência, no 58, p. 281-296, jul. 2009. Disponível em:

$<$ http://www.periodicos.ufsc.br>. Acesso em 20 ago. 2017.

SANTA CATARINA (ESTADO). Tribunal de Justiça do Estado de Santa Catarina. Mediação Familiar: Formação de Base. Florianópolis: 2004, 98p. Disponível em: $<$ http://www.tj.sc.gov.br>. Acesso em 20 ago. 2017.

SANTOS, Boaventura de Souza. A sociologia dos Tribunais e a democratização da justiça. In: SANTOS, Boaventura de Souza. Pela mão de Alice. São Paulo: Cortez, 1985.

SPENGLER, Fabiana Marion. Fundamentos Políticos da Mediação Comunitária. Ijuí: EditoraUnijuí, 2012.

. Uma nova abordagem dos conflitos sociojurídicos por meio do Direito Fraterno. Direito em Debate, n. 26, jul.-dez. 2006, p. 33-56. Disponível em: $<$ https://www.revistas.unijui.edu.br/index.php/revistadireitoemdebate/article/viewFile/6 76/393>. Acesso em 19 set. 2015.

SILVA, João Roberto da. A Mediação e o Processo de Mediação. São Paulo: Paulistanajur Edições, 2004.

SOARES, Samira Iasbeck de Oliveira. Mediação de Conflitos Ambientais: Um novo caminho pra a Governança da Água no Brasil?Curitiba: Editora Juruá, 2010.

TOCQUEVILLE, Aléxis. Democracia na América. Paris: s.n, 1963.

VASCONCELOS, Carlos Eduardo de. Mediação de Conflitos e Práticas Restaurativas. 2 ed., rev., atual. eampl. São Paulo: Editora Método, 2012. 


\section{AAPLICABILIDADE DO DIREITO FRATERNO NO ÂMBITO DA MEDIAÇÃO DE CONFLITOS COMO MÉTODO EXTRAJUDICIAL DE TRATAMENTO DE CONFLITO}

VEZZULA, Juan Carlos. A Mediação Comunitária: Desafios e Perspectivas. Revista da Faculdade de Direito UniRitter, 2010, p. 47-60. Disponível em:

$<$ http://seer.uniritter.edu.br/index.php/direito/article/viewFile/460/284>. Acesso em 20 ago. 2017.

VIEIRA, Liszt. Cidadania e Sociedade Civil no espaço público democrática.

Disponível em: <http://empreende.org.br>. Acesso em 20 ago. 2017.

WALTRICH, DhieimyQuelem; SPENGLER, Fabiana Marion. Reflexões acerca da Mediação Comunitária como Estratégia Prática de Cidadania Participativa. Revista de Estudos Jurídicos da UNESP, a. 17, n. 25, 2013, p. 161-181. Disponível em:

$<$ http://periodicos.franca.unesp.br/index.php/estudosjuridicosunesp/article/view/546>. Acesso em 20 ago. 2017.

WARAT, Luis Alberto.O oficio do mediador. Florianópolis: Habitus Editora, 2001. 